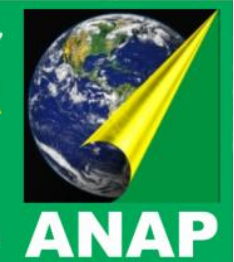

\title{
EROSÃO FLUVIAL NAS ESTAÇÕES DE PRIMAVERA E VERÃO DE 2010, NO CÓRREGO BOM JARDIM, EM BRASILÂNDIA/MS.
}

\author{
Agnes Cássia Dias Moraes Maciel ${ }^{1}$ \\ Felipe Amaro da Silva² \\ André Luiz Pinto
}

\begin{abstract}
Resumo: A Bacia do Córrego Bom Jardim se localiza no município de Brasilândia - MS, entre as

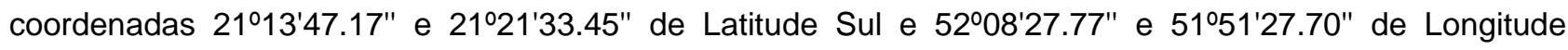
Oeste. Constitui uma das principais calhas de efluência do município, drenando diversas áreas das imediações urbanas, pastagens, solos expostos e duas reservas, a aldeia Ofayé-Xavante e RPPN Cisalpina. Predominando o uso agropecuário de suas terras, sem emprego de práticas conservacionistas de uso e manejo da terra e pequenas manchas de mata ciliar. O presente estudo visa avaliar a competência de transporte de sedimentos em suspensão nas águas da bacia do Bom Jardim, em duas estações chuvosas do ano. Para tanto foram realizadas saídas a campo para coletas de amostras de sedimentos em suspensão e mensuração da vazão, ao longo de oito estações.
\end{abstract}

Palavras Chave: sedimentos em suspensão, vazão, erosão fluvial.

\section{Introdução}

Os sedimentos encontrados em canais fluviais possuem origem, tamanhos e formas diferenciadas. Assim como os diferentes processos com que são formados, depositados e carregados através do canal. Muitos sedimentos são formados a partir das práticas agrícolas, como a criação de gado, que com o pisoteio dos animais ao redor do córrego acarreta na deposição de sedimentos e também no assoreamento das margens. A utilização de terras, construções civis e transporte aos arredores dos cursos d'água também influenciam na formação. Outro fator importante também é a própria ação erosiva que a água exerce sobre corpos rochosos nas margens e no fundo do canal. (CHRISTOFOLETTI, 1981) 


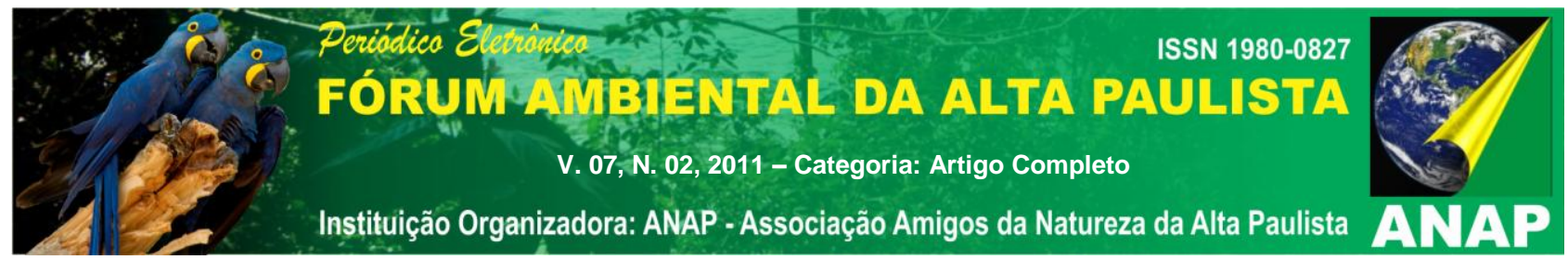

O processo de transporte dos sedimentos envolve a remoção, transporte e deposição dos mesmos. A remoção varia entre as atividades do homem, muitas vezes, totalmente prejudicial ao canal, e a ação da própria natureza, como a erosão. O transporte é influenciado através da área do canal, a força do escoamenteo e a espécie do sedimento a ser transportado. No processo de deposição é gerado o acúmulo de sedimentos que, geralmente ocorre nos locais do canal onde a força do escoamento se reduz, e variando o local da deposição, muitas vezes interrompe a passagem livre de água, acarretando na diminução do fluxo e aumentando os riscos de enchentes.

Inundação, deslizamento, estiagem, etc., são fenômenos naturais, observados com frequência na natureza, além disso, o aquecimento global aumenta a frequência e a intensidade de eventos de chuva, contribuindo no aumento da incidência de desastres naturais. São exemplos de desastres naturais: inundações, deslizamentos (ou escorregamentos), estiagem, erupções vulcânicas, furacões, vendavais, granizo, incêndio florestal, terremotos, raios, e tempestades (KOBIYAMA, et. al., 2006).

O córrego Bom Jardim, possui 8 (oito) pontos de análises e coletas de amostras, e somento o ponto 1 possui mata ciliar e cercamento que protegem o canal do pisoteio de animais, intempéries da natureza e carreamento excessivo de sedimentos. Nos demais pontos não há presença de mata ciliar, ocasionando vários pontos de escorregamentos, assoreando as margens do canal principal e seus afluentes.

A bacia do Córrego Bom Jardim foi escolhida devido a sua localização no município de Brasilândia/MS (Figura 1), agravado pelos assentamentos desenvolvidos pela Companhia Energética de São Paulo - CESP, que não tiveram rigorosa fiscalização do cumprimento da legislação ambiental, esta se encontra submetida a acelerado ciclo erosivo, pondo em risco a sede do município, a cidade de Brasilândia, onde grandes ravinamentos e voçorocamentos avançam sobre vias públicas e edificações prediais domiciliares e públicas. Além de assorear o lago da Usina Hidrelétrica de Porto Primavera, no rio Paraná. 

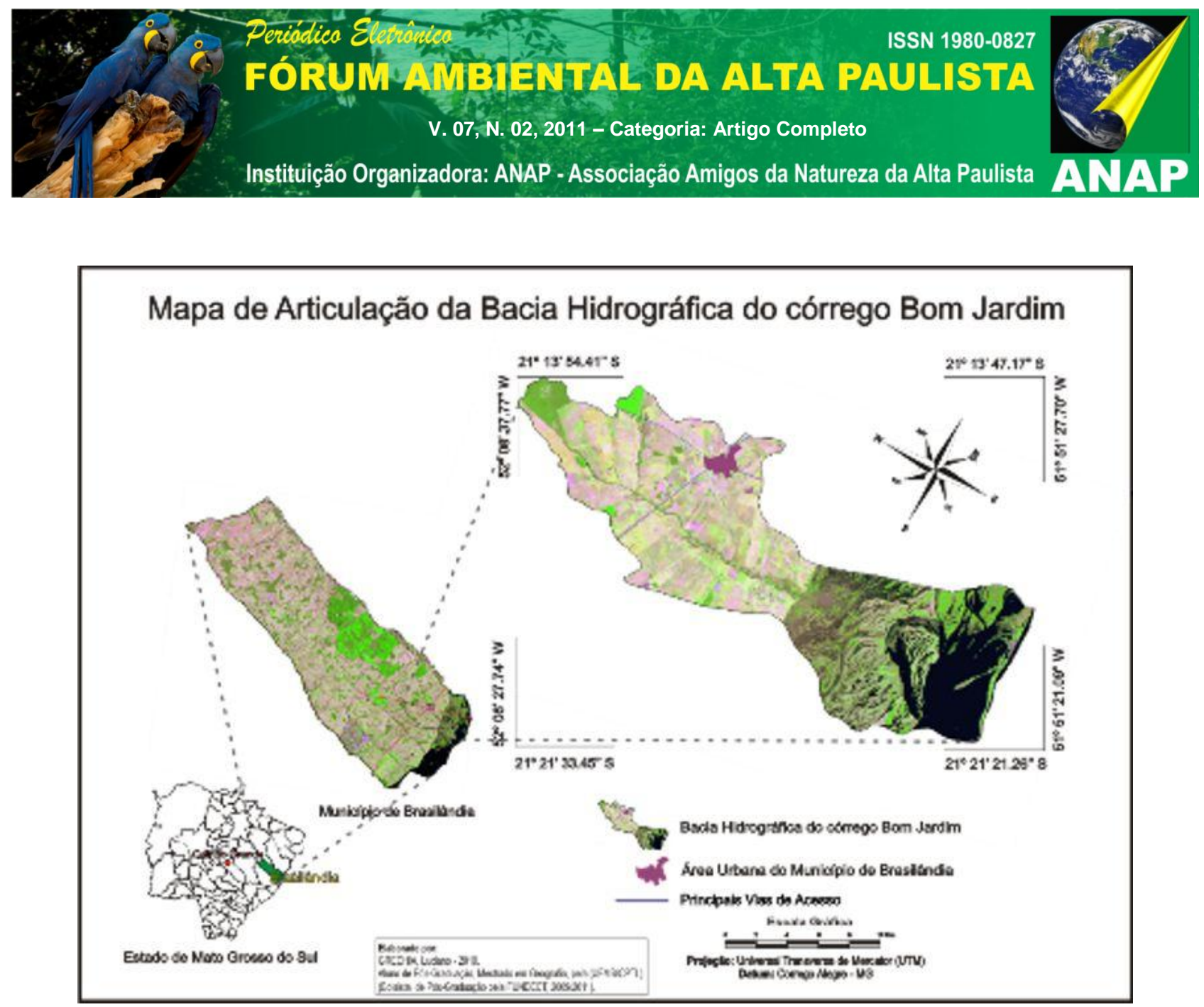

Figura 1: Mapa de localização

Fonte: GRECHIA, Luciano (2010)

O presente estudo justifica-se então, pela necessidade de ampliar os conhecimentos sobre o transporte de sedimentos em suspensão no canal fluvial, e as consequências geradas por esse processo para que possa predizer medidas básicas de planejamento e preservação da bacia hidrográfica do córrego Bom Jardim. 


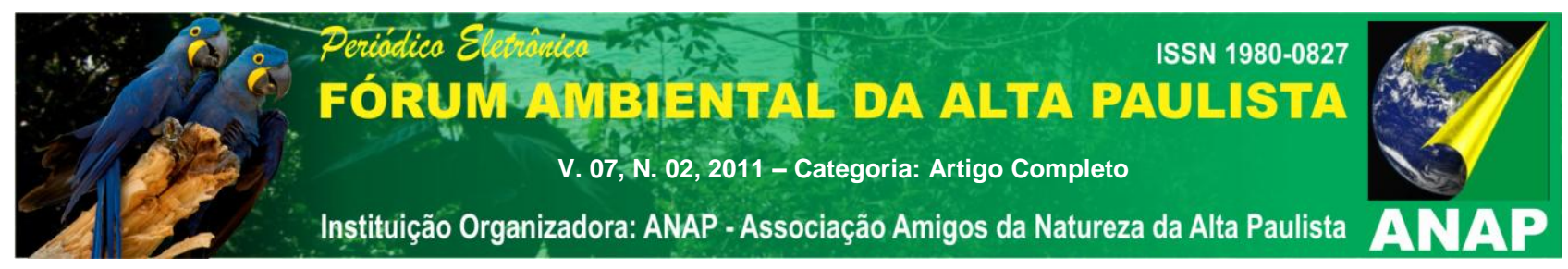

\section{Metodologia}

A carga de sedimento dos cursos de água é obtida pela ação erosiva que as águas exercem sobre todo o entorno da bacia e no fundo dos leitos, sendo que, no caso do Córrego Bom Jardim, há ocorrência de cobertura vegetal (mata ciliar) em pouquíssima quantidade, e associado com o tipo de solo friável que constitui toda a bacia. Devido a isso, deve-se reconhecer que os fatores hidrológicos que controlam as características e o regime dos cursos de água. A carga do leito do rio é composta por partículas de granulometria maior, como as areias e cascalhos, que são transportadas através da saltitação, deslizamento ou rolamento na superfície do leito. (PINTO et. al., 2010).

Ao longo do córrego Bom Jardim há presença de animais, principalmente criações de gado, que utilizam o canal para beber água. Com isso, nas margens, ficam os sinais do pisoteio (Figura 2) que se agravam, podendo aumentar a assoreação e assim aumentando o carregamento de sedimentos no local. Além do aumento de sedimentos, esses animais depositam materiais fisiológicos influenciando também no carregamentos de matéria orgânica.

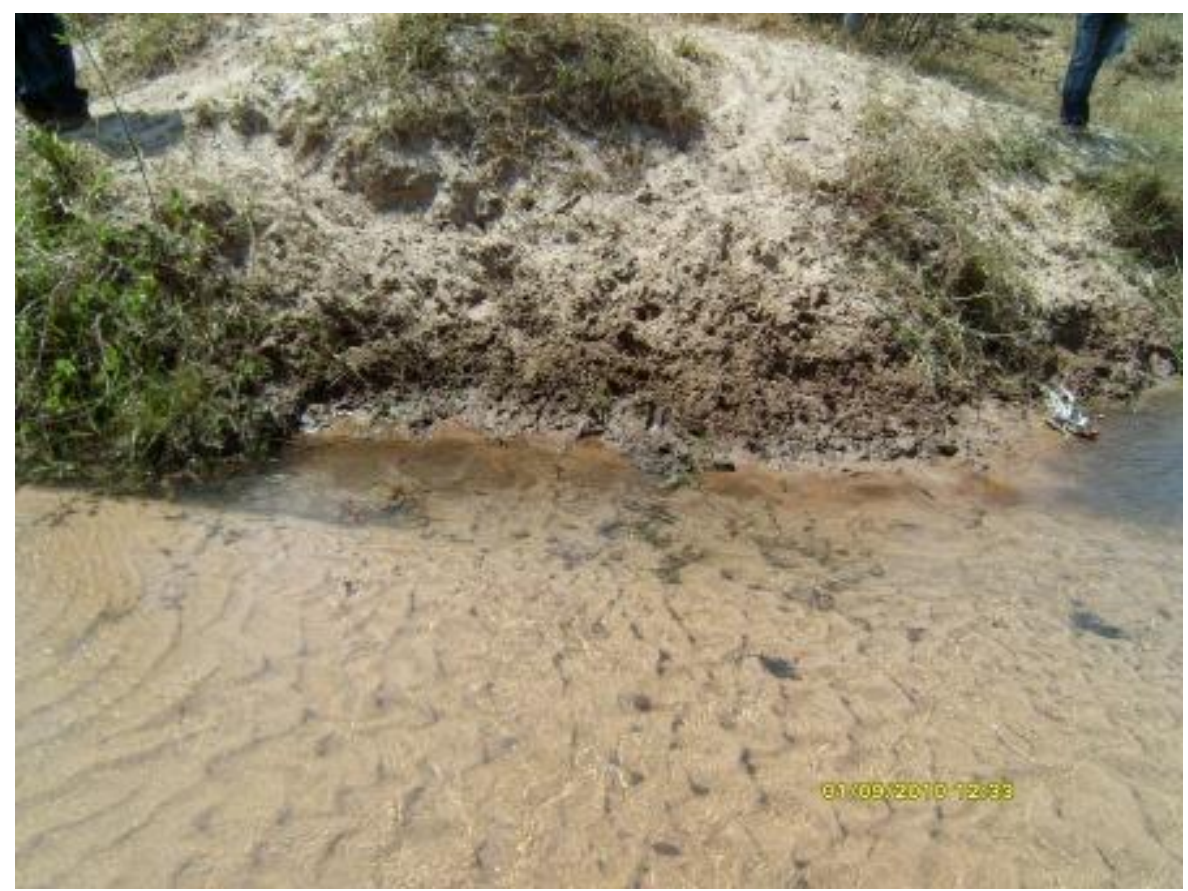

Figura 2: Sinais de pisoteio animal e grande depósito de sedimentos. Foz do córrego Sete de Setembro, no Bom Jardim..

Fonte: Dias (2010). 


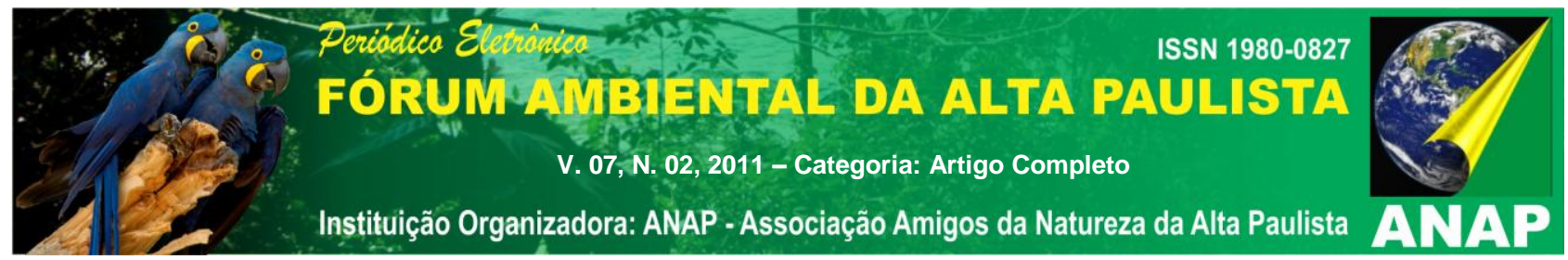

Em laboratório, para a realização das análises, registros e qualificação foi utilizada a ferramenta Corel Draw, o programa Word, uma câmera digital, um GPS, o programa Excel, e dados bibliográficos e webgráficos.

Para a competência fluvial e o reconhecimento das aréas que apresentam riscos, foram realizadas visitas a campo, onde foram realizadas coletas de amostras de água, para os calculos de competência fluvial nos respectivos pontos e foram retiradas fotos dos locais, para melhor visualização da mata ciliar e do solo ao longo do canal principal e seus afluentes, podendo assim realizar uma melhor avaliação dos riscos. Risco é um conceito importante porque nos permite pensar em termos de probabilidade tanto no que se refere à frequência quanto aos lugares de ocorrência. Permite, portanto, promover o planejamento a partir de um olhar prospectivo. Evidentemente, disso depende um amplo conhecimento da dimensão contextual da produção do perigo, seus danos potenciais, incidência e distribuição (AMARO, 2011).

A cobertura vegetal desempenha papel importantíssimo na diminuição do escoamento imediato das águas pluviais auxiliando o solo na tarefa de absorção pela infiltração lenta e eficiente (MARCELINO, 2006).

Devidos a esses conceitos e informações a observação em campo se fez importantissima, o registro e coletas realizadas nas áreas para uma melhor análise e cálculos em laboratório.

\section{Discussão e Resultados}

De acordo com os estudos realizados, foi possível observar a grande fragilidade da área, devido a vários fatores como a reduzida cobertura vegetal, em especial ciliar, a precária utilização de práticas conservacionistas empregadas no uso, ocupação e manejo da terra, produzidas pela ação antrópica associadas às fragilidades ambientais naturais de seus solos friáveis e pouco coesos, derivados do arenito do grupo Bauru, que pesar da baixa declividade, entre 0 a 3\%, influem na elevada competência fluvial de transportes de sedimentos. Que além, de assorearem o médio e baixo curso da 


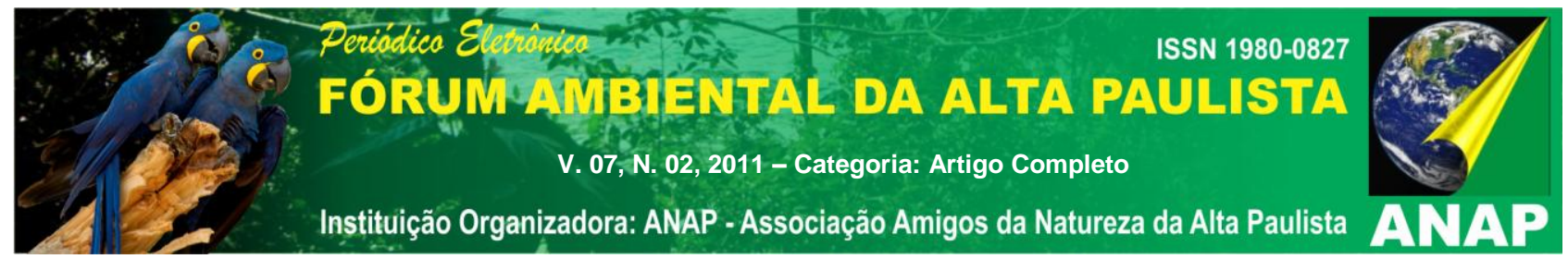

bacia do Bom Jardim e de sua foz no rio Paraná, no lago da represa de Porto Primavera, compromete a qualidade de suas águas superficiais e de vida da população da cidade de Brasilândia cortada por seu afluente, da biodiversidade da Reserva do Patrimônio Particular Natural - RPPN da Cisalpina e da aldeia indígena Ofayé Xavante.

Com as coletas realizadas nos pontos de análises, foi possível observar a quantidade de sedimentos carreados durante o ano de 2010, notou-se a grande quantidade de toneladas de sedimentos na estação da primavera, 164.075, 85 toneladas, como mostra a Tabela 1.

Tabela 1 - Competência fluvial, em toneladas por estação, do córrego Bom Jardim, Brasilândia/MS. Primavera -2010 .

\begin{tabular}{c|c|c|c}
\hline Pontos & \multicolumn{3}{|c}{ Competência Fluvial } \\
\hline $\mathbf{1}$ & $\mathbf{g} / \mathbf{1 0 0} \mathbf{~} \mathbf{l}$ & $\mathbf{g} / \mathbf{m}^{\mathbf{3}} \mathbf{s}$ & Ton/Estação \\
\hline $\mathbf{2}$ & 0,0011 & 44,99 & 349,84 \\
\hline $\mathbf{3}$ & 0,0020 & $1.219,20$ & $9.480,50$ \\
\hline $\mathbf{4}$ & 0,0082 & $1.875,34$ & $14.582,64$ \\
\hline $\mathbf{5}$ & 0,0020 & $2.373,20$ & $18.454,00$ \\
\hline $\mathbf{6}$ & 0,0018 & $1.627,92$ & $12.658,71$ \\
\hline $\mathbf{7}$ & 0,0171 & 44,46 & 345,72 \\
\hline $\mathbf{8}$ & 0,0018 & $2.461,50$ & $19.140,62$ \\
\hline TOTAL & 0,0181 & $11.453,68$ & $\mathbf{1 6 9 . 0 6 3 , 8 2}$ \\
\hline
\end{tabular}

Decorrente da grande quantidade de sedimentos carreados na primavera foi possivel observar, que, também houve um maior impacto ambiental, principalmente nas margens do córrego Sete de Setembro, como mostra a Figura 4. 

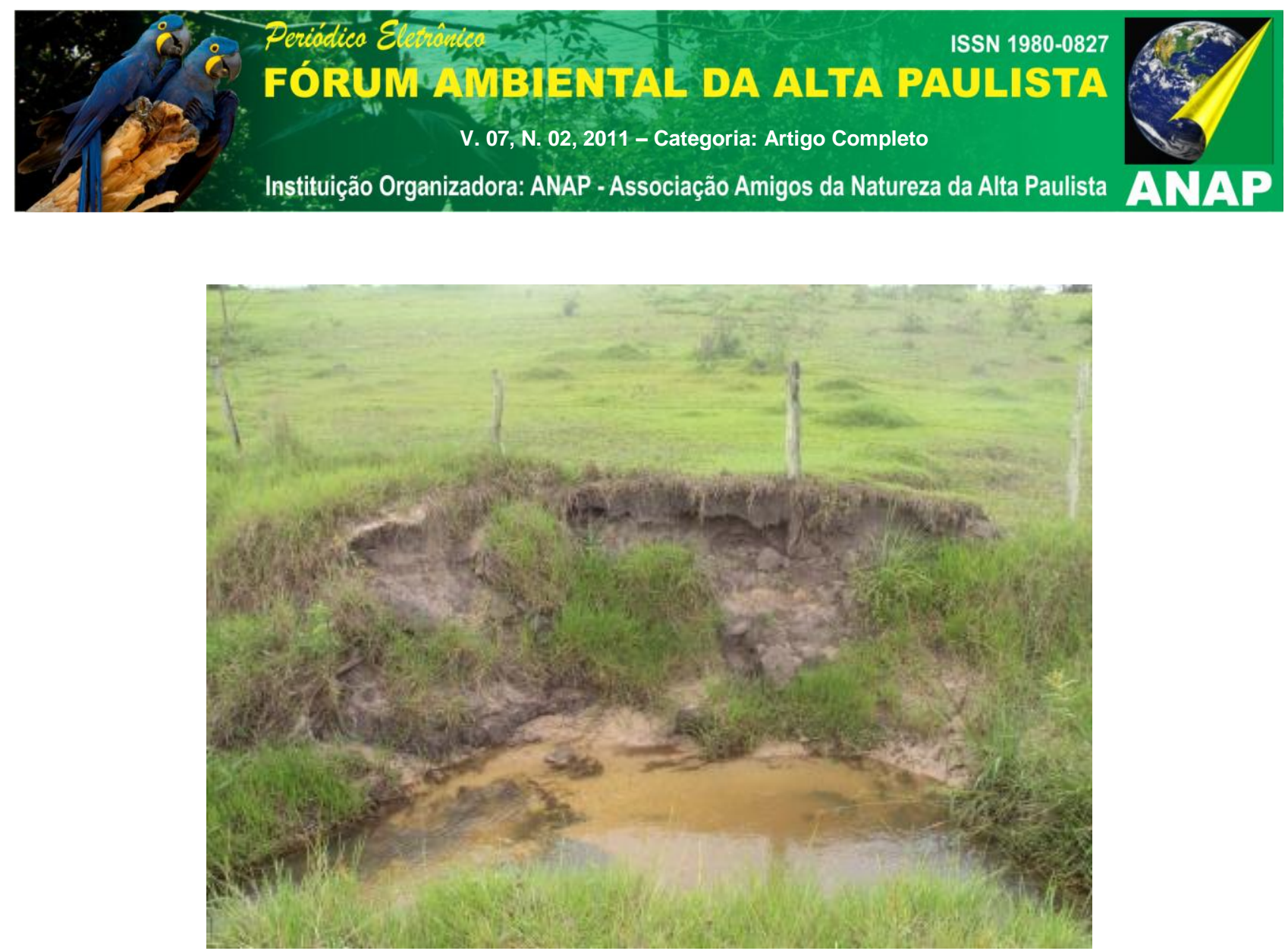

Figura 3: Margem esquerda do córrego Sete de Setembro, em seu baixo curso.

Fonte: Dias (2010).

A estação do verão 2010, tambem apresentou um grande carreamento de sedimentos, como mostra a Tabela 2.

Tabela 2 - Competência fluvial, em toneladas por estação, do córrego Bom Jardim, Brasilândia/MS. Primavera - 2010.

\begin{tabular}{c|c|c|c}
\hline Pontos & \multicolumn{3}{|c}{ Competência Fluvial } \\
\hline $\mathbf{1}$ & $\mathbf{g} / \mathbf{1 0 0} \mathbf{~} \mathbf{l}$ & $\mathbf{g} / \mathbf{m}^{\mathbf{3}} \mathbf{s}$ & Ton/Estação \\
\hline $\mathbf{2}$ & 0,0018 & 86,40 & 671,85 \\
\hline $\mathbf{3}$ & 0,0912 & $9.530,40$ & $74.108,39$ \\
\hline $\mathbf{4}$ & 0,0019 & 114,57 & 890,90 \\
\hline $\mathbf{5}$ & 0,0045 & $1.216,35$ & $9.458,34$ \\
\hline $\mathbf{6}$ & 0,0015 & 295,20 & $2.295,47$ \\
\hline $\mathbf{7}$ & 0,0767 & $5.108,22$ & $39.721,52$ \\
\hline $\mathbf{8}$ & 0,0017 & 837,59 & $6.513,10$ \\
\hline TOTAL & 0,0015 & 786,45 & $6.115,43$ \\
\hline
\end{tabular}




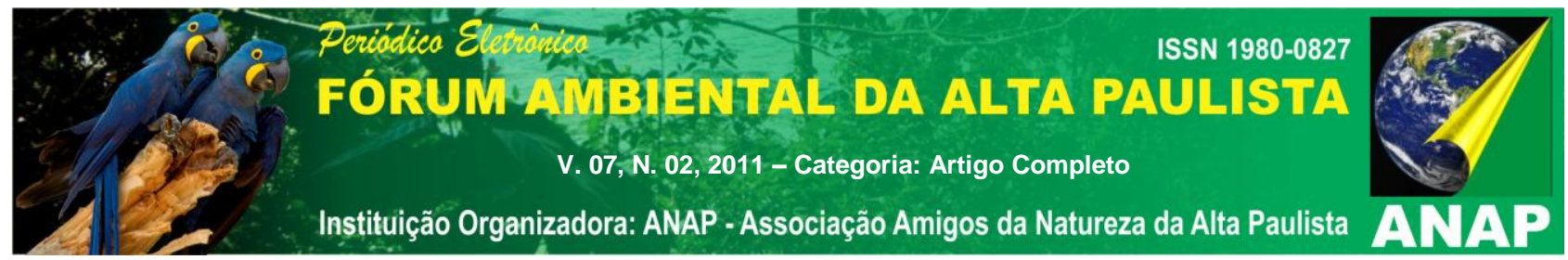

As estações da primavera e do verão são consideradas épocas do ano de reposição, o ano de 2010 pôde ser considerado típico devido as épocas de estiagem (outono e inverno) e reposição serem bem caracterizadas em questão das chuvas.

Durante as estações da primavera e verão o córrego Bom Jardim depositou cerca de 303.850,85 toneladas de sedimentos, o que corresponde, aproximadamente, a $78 \%$ de toda a carga do ano, sendo assim, os outros $22 \%$ (aproximadamente $82.962,37$ toneladas) se dividindo nas estação de estiagem (outono e inverno).

O valor total do ano de 2010 (386.813,22 toneladas) de sedimentos carreados é um número consideravelmente grande, sendo que todo esse material é depositado na sua foz no rio Paraná, no lago da represa de Porto Primavera, comprometendo não só as margens do rio como também a qualidade de suas águas superficiais e de vida da população da cidade de Brasilândia.

\section{Considerações Finais}

Conclui-se que o acelerado processo erosivo fluvial, esta gerando elevada dissecação, transporte e deposito, assoreando os pontos de menor energia do relevo, em especial na foz dos afluentes pela margem esquerda o Sete de Setembro e o Aviação, e na entrada da RPPN Cisalpina, posicionada no baixo curso do Bom Jardim e um patamar estrutural repleto de paleocanais reafogados pelo lago da represa de Porto Primavera.

Tal assoreamento além de ser resultante de perda de solo, provoca a redução da quantidade e da qualidade das águas da bacia, enchentes na primavera e verão, e na estiagem, sobre tudo no inverno brusca queda da vazão.

A solução simples para redução das dissecações e transporte de sedimentos é o cercamento das áreas de mata ciliar e sua recomposição com matas nativas, e o uso de praticas conservacionista de cultivo e de manejo agrícola e pecuário.

\section{Referências}




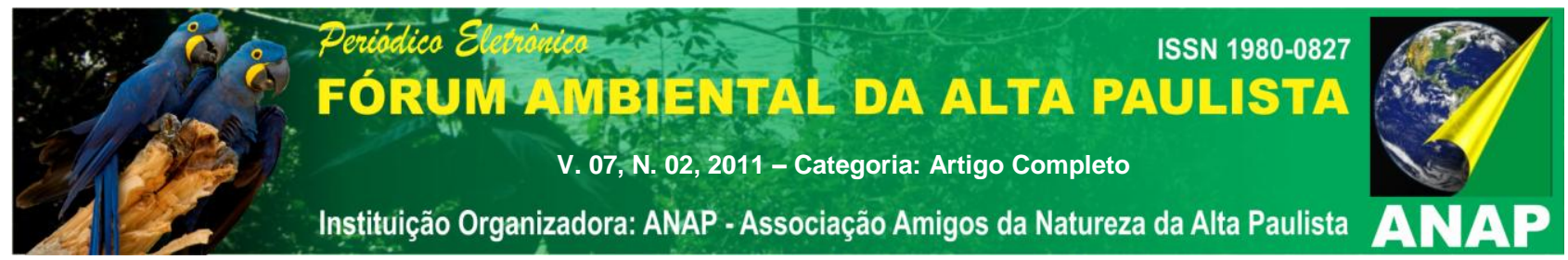

AMARO, F. S; PERCEPÇÃO DOS DESASTRES AMBIENTAIS CLIMÁTICOS EM JARAGUÁ DO SUL - SC. Monografia. Três lagoas/ MS: UFMS, $21 \mathrm{p}$.

CARVALHO, N. de O. Hidrossedimentologia prática. $2^{\mathrm{a}}$ ed., ver., atual. ampliada - Rio de Janeiro: Interciência, p. 4 a 11 e 73 a 80. 2008

CESP Plano de Manejo da Reserva Cisalpina. Companhia Energética de São Paulo: Relatório. São Paulo, 2007: 234p.

CETESB. Companhia de Tecnologia de Saneamento Básico. Guia de coleta e preservação de amostras de água. São Paulo, 1987: 150p. (Séries guias)

CHRISTOFOLETTI, A. Geomorfologia Fluvial. Vol. 1 - São Paulo: Edgard Blücher, p. 21 a 40, 1981.

KOBIYAMA et al. 2006. Prevenção de desastres naturais: Conceitos básicos.

Curitiba: Ed. Organic Trading. 109 p. Disponível em:

HTTP://www.labhidro.ufsc.br/publicacoes.html.

MACIEL, A. C. D. M; EVOLUÇÃO DA QUALIDADE E DO ENQUADRAMENTO DAS ÁGUAS SUPERFICIAIS DA BACIA DO CÓRREGO BOM JARDIM, BRASILÂNDIA/MS. Monografia. Três Lagoas/ MS: UFMS, 2011, 61 p.

MARCELINO, E. V. et al Mapeamento de risco de desastres naturais do Estado de Santa Catarina. Caminhos de Geografia, Uberlândia, n. 8, v. 17, p. 72-89, fev. 2006. Disponível em: http://www.ig.ufu.br/revista/caminhos.html

PINTO, A. L. ; A importancia do Ribeirão Claro para o Abastecimento de água da cidade de Rio Claro-SP. In:Geografia Teorética-vol.15 1985. 